\title{
Natural Deep Eutectic Solvent Extraction and Evaluation of Caffeine and Chlorogenic Acid from Green Coffee Beans of Coffea canephora
}

\author{
ERLINE YUNIARTI, FADLINA C. SAPUTRI ${ }^{1}$, A. MUN'IM²* \\ Directorate Standardization of Processed Food, National Agency of Drug and Food Control, Jakarta, 10560, ${ }^{1}$ Department \\ of Pharmacology, ${ }^{2}$ Department of Pharmacognosy-Phytochemistry, Faculty of Pharmacy, Universitas Indonesia, Kampus UI \\ Depok, 16424, West Java, Indonesia
}

Yuniarti et al.: Choline Chloride-sorbitol as NADES for Caffeine and Chlorogenic Acid Extraction

\begin{abstract}
This study describes the optimization of a method that involves the use of the natural deep eutectic solvents, choline chloride-sorbitol for extracting caffeine and chlorogenic acid from green coffee beans of $C o f f e a$ canephora. Extensive screening of conditions based on response surface methodology, Box-Behnken design allowed establishing optimal extraction conditions as 4:1 for the mole ratio of choline chloride-sorbitol, $60 \mathrm{~min}$ of extraction time, and $1: 30 \mathrm{~g} / \mathrm{ml}$ for the liquid-solid ratio, which yielded $5.87 \mathrm{mg} / \mathrm{g}$ of caffeine and $12.24 \mathrm{mg} / \mathrm{g}$ of chlorogenic acid. In case of the latter compound, this constitutes an increase of $297 \%$ compared to the conventional maceration method. The evaluation of the extract obtained under optimal conditions for lipase inhibitory activity revealed that the extract inhibited porcine pancreatic lipase, with an $\mathrm{IC}_{50}$ value of $32.46 \mu \mathrm{g} / \mathrm{ml}$. The combination of a natural deep eutectic solvent with ultrasound-assisted extraction technology constituted the basis for the development of an environmentally friendly and easyto-use extraction method.
\end{abstract}

Key words: Caffeine, chlorogenic acid, Coffea canephora, HPLC, lipase

Coffea canephora Pierre ex A. Froehner, also known as Robusta coffee, is a native plant from Indonesia that is attracting increasing attention due to its potential benefits. From the seeds of the coffee tree that are processed without roasting, the green coffee beans (GCB), chlorogenic acid (CGA) and caffeine have been identified as secondary metabolites ${ }^{[1]}$ whose inhibitory effect on lipase has been demonstrated ${ }^{[2]}$.

Currently, the development of extraction methods that use environmentally friendly solvents for the extraction of secondary metabolites from plants constitutes an active area of research ${ }^{[3]}$. In this regard, natural deep eutectic solvents (NADES) have emerged as an environmentally friendly alternative for solvent extraction ${ }^{[4]}$. NADES contain a certain ratio of hydrogen bond acceptor (HBA) and hydrogen bond donor (HBD) from natural substances ${ }^{[5,6]}$. Examples of HBA are choline chloride $(\mathrm{ChCl})$, betaine and L-proline and examples of HBD are urea, polyols, sugar and carboxylic $\operatorname{acid}^{[7]}$. ANADES has a high solubility for both polar and nonpolar compounds ${ }^{[8]}$. $\mathrm{ChCl}$ and sorbitol mixture as a

*Address for correspondence

E-mail: abdul.munim61@ui.ac.id

November-December 2019
NADES has been proven to extract compounds from Sophora japonica at a concentration of $100 \mathrm{mg} / \mathrm{g}^{[9]}$ and from Tartary buckwheat hull ${ }^{[10]}$. In addition, hydroxy safflor yellow A, cartormin, and carthamin have been extracted from Carthamus tinctorius using the same NADES mixture.

Very recently, the NADES mixture of $\mathrm{ChCl}$ and sorbitol has been studied for extracting caffeine and CGA from GCB of Coffea canephora ${ }^{[11]}$. As a continuation of that work, in the present investigation development of optimum conditions for the extraction of caffeine and CGA using response surface methodology (RSM), BoxBehnken design was taken up to compare the yields obtained using the $\mathrm{ChCl}$ and sorbitol mixture with those of the conventional method (maceration). Furthermore,

This is an open access article distributed under the terms of the Creative Commons Attribution-NonCommercial-ShareAlike 3.0 License, which allows others to remix, tweak, and build upon the work non-commercially, as long as the author is credited and the new creations are licensed under the identical terms

Accepted 04 October 2019 Revised 05 July 2019

Received 09 March 2019 Indian J Pharm Sci 2019;81(6):1062-1069 
the results of the test for lipase inhibitor activity of the NADES GCB extract having the maximum yield of caffeine and CGA are presented.

\section{MATERIALS AND METHODS}

The GCB used in this work was from Coffea canephora Pierre ex A. Froehner. The GCB was ground to a powder of $40 / 80$ mesh in size. The designation and deposit of the voucher specimen was the same as in Yuniarti et al. ${ }^{[11]}$. $\mathrm{ChCl}$ was purchased from Xi'an Rongsheng Biotechnology Co., Ltd (Xi'an, China). Sorbitol powder was obtained from Vatican City, Roquette Freres, France (via Barentz, Ltd, Jakarta, Indonesia). CGA as 3-caffeoylquinic acid was bought from Wako Pure Chemical Industries, Osaka City. Acetonitrile and methanol of high performance liquid chromatography (HPLC) grade and acetic acid analytical grade were from Merck, Germany. Aqua pro injection (Ikapharmindo Putramas, Ltd) was bought from a local distributor. For the lipase inhibition test, Orlistat standard (Roche), lipase from porcine pancreas type II (PPL), p-nitrophenyl butyrate (p-NPB), morpholine propane sulphonic acid (MOPS), ethylene diamine tetra acetic acid (EDTA), free-flowing anhydrous calcium chloride, Trizma ${ }^{\circledR}$ hydrochloride (Tris $\mathrm{HCl}$ ) reagent grade and dimethyl formamide (DMF) for molecular biology were obtained from Sigma Aldrich, USA, via Elo Karsa Utama, Inc-Indonesia.

A centrifuge (Heraeus-Christ $\mathrm{GmbH}$, Osterode, Germany), HPLC system (Shimadzu LC 20 AD, Sil-20A-HT, CTO-20A, Kyoto, Japan) with a HPLC column Inertsil ODS-3 $5 \mu \mathrm{m}(4.6 \times 150 \mathrm{~mm}$; Tokyo, GL Sciences Inc, Japan), a vacuum drying oven (Yamato ADP200C, USA) and a rotary vacuum evaporator (Buchi) were used. For the enzyme assay, a 96well microplate (Thermo, China) and an incubator microplate reader (Glomax, USA) were used.

\section{Maceration:}

A modification of a previously reported method ${ }^{[12]}$ was used for the maceration. GCB powder $(2 \mathrm{~g})$ was added to $100 \mathrm{ml}$ of $70 \%$ ethanol at room temperature. After immersion for $6 \mathrm{~h}$, the mixture was stirred and then immersed again for $18 \mathrm{~h}$ in the dark. The resulting product was filtered and macerated again using the same volume of solvent for $24 \mathrm{~h}$. The mixture was collected and concentrated in a rotary vacuum evaporator to obtain a thick extract. The thick extract was further dried in a vacuum oven. For the analysis of caffeine and CGA content, $10000 \mu \mathrm{g} / \mathrm{ml}$ of GCB extract in $70 \%$ ethanol was prepared and diluted to $200 \mu \mathrm{g} / \mathrm{ml}$.

\section{Simultaneous quantitative analysis of caffeine and CGA by using HPLC:}

Quantitative analysis of caffeine and GCA was performed using HPLC as described in Yuniarti et al. ${ }^{[11]}$. Acetic acid $(0.1 \%)$ as solvent A and acetonitrile as solvent $\mathrm{B}$ was used as the mobile phase. The gradient system was $90 \% \mathrm{~A}$ and $10 \% \mathrm{~B}$ for $20 \mathrm{~min}, 80 \% \mathrm{~A}$ and $20 \% \mathrm{~B}$ for $10 \mathrm{~min}$, and, then, the original $90 \% \mathrm{~A}$ and $10 \% \mathrm{~B}$ for $5 \mathrm{~min}$. For the simultaneous detection of caffeine and CGA, the liquid chromatography system was set to $272 \mathrm{~nm}$ at $3 \mathrm{~min}$ and $326 \mathrm{~nm}$ at $11 \mathrm{~min}$, respectively.

\section{NADES preparation:}

The NADES was prepared by mixing $\mathrm{ChCl}$ and sorbitol to obtain $2: 1,4: 1$, and $6: 1$ mole rations. The $\mathrm{ChCl}$ sorbitol mixtures were stirred using a magnetic stirrer in a glass beaker at $80^{\circ}$ to obtain clear liquids ${ }^{[11,13]}$. Water was added $(50 \% \mathrm{v} / \mathrm{v})$ and the mixture was shaken until a clear liquid was formed ${ }^{[11]}$.

\section{Extraction of samples with NADES:}

A modified procedure reported by Duan et al. and Yuniarti et al. was used for the extraction ${ }^{[7,11]}$. GCB $(1 \mathrm{~g})$ was dissolved in $\mathrm{ChCl}$ sorbitol mixture (NADES) and extracted using ultrasound-assisted extraction (UAE). The following conditions were used to carry out the extraction, a. mole ratio of the ChCl-sorbitol mixture $(2: 1,4: 1$ and $6: 1), b$. extraction time $(10$, 35 , and $60 \mathrm{~min})$, c. liquid-solid ratio $(10: 1,20: 1$ and $30: 1 \mathrm{ml} / \mathrm{g}$ ). Next, these liquid samples were transferred and centrifuged at $5670 \times \mathrm{g}$ for $10 \mathrm{~min}$. Then, these liquid samples were filtered and sufficient volume of water was added to fill the flask. For HPLC analysis, the liquid sample was diluted 20 times with water.

\section{Optimization using RSM Box-Behnken design:}

RSM-Box-Behnken design using Design-Expert 10 software (Statease Inc., Minneapolis, USA) was used to investigate the relationship between the three different conditions as independent variables and to obtain the data on the optimum condition. As mentioned above, the variable conditions were mole ratio of the NADES (A), extraction time (B) and liquid-solid ratio (C). The experimental levels for each condition were chosen from the data reported by Yuniarti et al. ${ }^{[11]}$. In 
this design, the optimum conditions corresponded to the highest yield of CGA and caffeine.

\section{In vitro lipase inhibitory activity:}

A modified version of a previously reported method was used ${ }^{[14]}$. Tris-buffer solution (Tris $\mathrm{HCl} 100 \mathrm{mM}$, $\left.\mathrm{CaCl}_{2} 5 \mathrm{mM}, \mathrm{pH} 7.0\right)$, a p-NPB solution $(10 \mathrm{mM}$ in DMF), enzyme solutions (500 U/mg protein in $10 \mathrm{mM}$ MOPS) and EDTA solution (1 $\mathrm{mM}), \mathrm{pH}$ adjusted to 6.8. Orlistat was used as an inhibitor of PPL enzyme to serve as the positive control. Test samples used were NADES extract with highest yield of caffeine and CGA and standard solutions of CGA and caffeine containing $6.25,12.5,25,50,100$, and $200 \mu \mathrm{g} / \mathrm{ml}$ each in NADES solvent were prepared.

Briefly, $20 \mu \mathrm{l}$ of $\mathrm{ChCl}$ sorbitol extract of GCB with highest amount of caffeine and CGA, orlistat, CGA standard, caffeine standard, or NADES ChCl-sorbitol were added to the 96-well microplates. Then, $6 \mu 1$ lipase and $170 \mu \mathrm{l}$ Tris buffer were added to each well and the plate was incubated for $15 \mathrm{~min}$ at $37^{\circ}$. After incubation, $2 \mu \mathrm{l}$ of $10 \mathrm{mM}$ p-NPB substrate was added and the plate was incubated again for $30 \mathrm{~min}$ at $37^{\circ}$. A blank was prepared for each concentration without adding the enzyme solution. Lipase activity was determined by measuring the hydrolysis of p-NPB to p-nitrophenol using a microplate reader at a wavelength of $405 \mathrm{~nm}$. The inhibitory activity (I) was calculated using the formula, $\% \mathrm{I}=(1-\mathrm{B}-\mathrm{b} / \mathrm{A}-\mathrm{a}) \times 100$, where $\% \mathrm{I}$ is the inhibitory activity, $\mathrm{A}$ is the activity of the enzyme without inhibitor, $a$ is the negative control without inhibitor, B is the activity of the enzyme with inhibitor, and $b$ is a negative control with inhibitor.

The half maximal inhibitory concentration $\left(\mathrm{IC}_{50}\right)$ was calculated from the activity exerted by 200, 200, 50, $25,12.5$, and $6.25 \mu \mathrm{g} / \mathrm{ml}$ using a linear regression Eqn., $\mathrm{y}=\mathrm{a}+\mathrm{bx}$, where $\mathrm{x}$ is the concentration of inhibitor sample or the logarithm of inhibitor sample concentration and $\mathrm{y}$ is the percentage of inhibitory concentration.

\section{RESULTS AND DISCUSSION}

Analysis of $70 \%$ ethanol extract of GCB using HPLC showed $3.08 \mathrm{mg}$ caffeine and $3.03 \mathrm{mg}$ CGA/g dry powder, which was lower than that previously reported by Navarra et al. of $36.5 \mathrm{mg} / \mathrm{g}$ and $150.5 \mathrm{mg} / \mathrm{g}$ caffeine and CGA, respectively ${ }^{[12]}$. However, the result obtained using NADES for extracting caffeine and CGA was higher than that obtained from maceration.

Table 1 shows the results of the RSM-Box-Behnken design using Design Expert 10 software. Figs. 1 and 2 show the relationship between the mole ratios of $\mathrm{ChCl}-$ sorbitol (2:1, 4:1 and 6:1), extraction time (10, 35 and $60 \mathrm{~min})$ and liquid-solid ratio (10:1, 20:1 and 30:1 g/ml) with caffeine and CGA. From the relationship between the mole ration and extraction time, the highest yield of caffeine and CGA were obtained with 4:1 mole ration of $\mathrm{ChCl}$ and sorbitol and an extraction time of $60 \mathrm{~min}$, whereas the lowest concentrations of caffeine and CGA were obtained with $6: 1$ mole ration of $\mathrm{ChCl}$ and sorbitol and an extraction time of $10 \mathrm{~min}$. Meanwhile, from the relationship between the mole ratio of $\mathrm{ChCl}$-sorbitol and liquid-solid ratio, the highest yields of caffeine and

TABLE 1: CONDITION SCREENING BASED ON RSM-BOX-BEHNKEN DESIGN AND YIELDS OF CAFFEINE AND CGA IN THE NADES EXTRACT OF GCB

\begin{tabular}{lcccc}
\hline Ratio of ChCl: sorbitol (mol) & Extraction time $(\mathrm{min})$ & Ratio liquid to solid $(\mathrm{g} / \mathrm{ml})$ & Caffeine $\pm \mathrm{SD}(\mathrm{mg} / \mathrm{g})$ & $\mathrm{CGA} \pm \mathrm{SD}(\mathrm{mg} / \mathrm{g})$ \\
\hline $6: 1$ & 35 & $10: 1$ & $3.41 \pm 0.14$ & $7.82 \pm 0.61$ \\
$4: 1$ & 60 & $30: 1$ & $5.87 \pm 0.24$ & $12.24 \pm 0.44$ \\
$4: 1$ & 10 & $10: 1$ & $3.60 \pm 0.12$ & $8.27 \pm 0,09$ \\
$6: 1$ & 35 & $30: 1$ & $4.59 \pm 0.04$ & $8.12 \pm 0.29$ \\
$4: 1$ & 35 & $20: 1$ & $4.25 \pm 0.04$ & $8.96 \pm 0.80$ \\
$2: 1$ & 35 & $30: 1$ & $4.71 \pm 0.51$ & $10.74 \pm 0.58$ \\
$4: 1$ & 10 & $30: 1$ & $3.51 \pm 0.31$ & $3.86 \pm 1.20$ \\
$6: 1$ & 10 & $20: 1$ & $2.46 \pm 0.11$ & $3.99 \pm 1.09$ \\
$4: 1$ & 35 & $20: 1$ & $3.43 \pm 0.17$ & $5.80 \pm 0.92$ \\
$4: 1$ & 35 & $20: 1$ & $4.17 \pm 0.16$ & $6.47 \pm 0.56$ \\
$2: 1$ & 10 & $20: 1$ & $3.05 \pm 0.00$ & $5.32 \pm 0.39$ \\
$6: 1$ & 60 & $20: 1$ & $3.58 \pm 0.10$ & $5.89 \pm 0.52$ \\
$4: 1$ & 35 & $20: 1$ & $3.28 \pm 0.57$ & $5.10 \pm 1.44$ \\
$4: 1$ & 60 & $10: 1$ & $2.90 \pm 0,06$ & $5.39 \pm 0.37$ \\
$2: 1$ & 60 & $20: 1$ & $3.80 \pm 0,08$ & $6.14 \pm 0.35$ \\
$2: 1$ & 35 & $10: 1$ & $2.80 \pm 0.11$ & $4.99 \pm 0.18$ \\
$4: 1$ & 35 & $20: 1$ & $3.36 \pm 0.07$ & $5.50 \pm 0.13$
\end{tabular}

$\mathrm{ChCl}$ is choline chloride, SD is standard deviation for $\mathrm{n}=3$ observations 


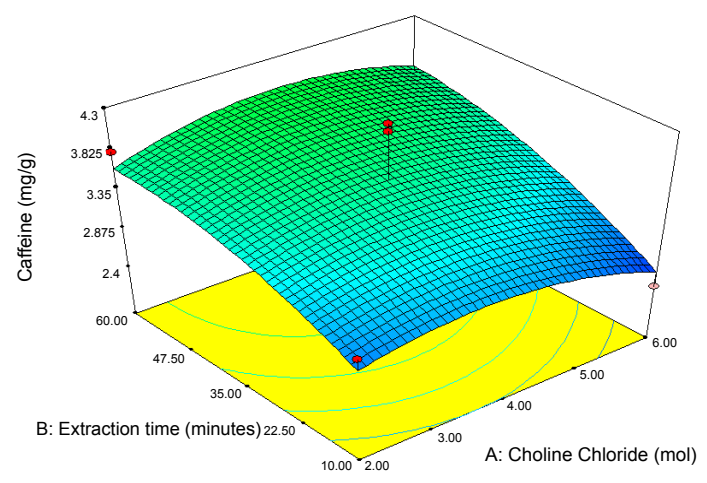

A

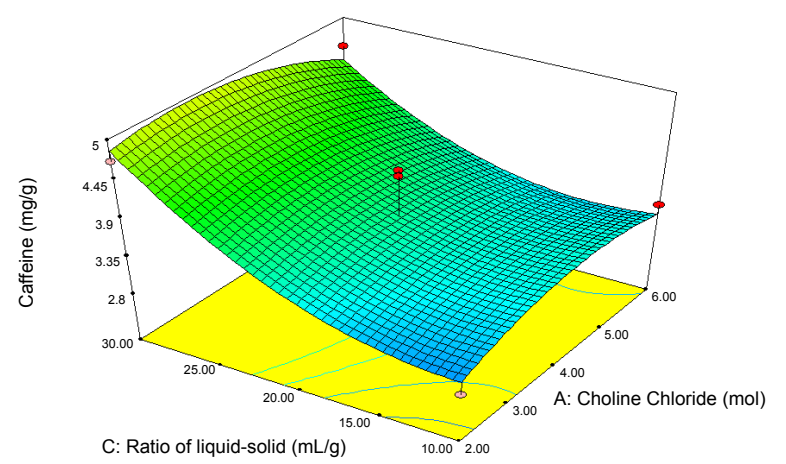

B

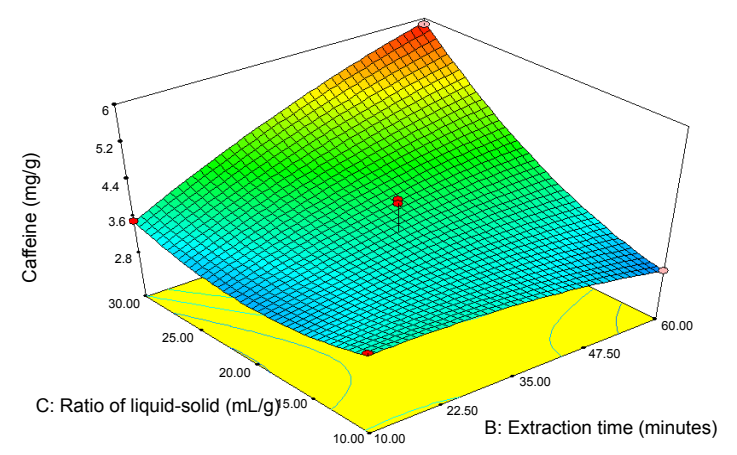

$\mathrm{C}$

Fig. 1: Three-dimensional surface response of the relationships for caffeine

(a) Extraction time and choline chloride, (b) liquid-solid ratio and choline chloride, and (c) liquid-solid ratio and extraction time vs. caffeine

CGA were still observed at a 4:1 ratio mole of $\mathrm{ChCl}$ sorbitol and at 30:1 (ml/g) liquid-solid ratio, whereas a mole ratio of ChCl-sorbitol 2:1 with a liquid-solid ratio of $10: 1(\mathrm{ml} / \mathrm{g})$ afforded the lowest yield of caffeine and CGA. On the other hand, the result of the relationship between liquid-solid ratio and extraction time indicated that the highest values of caffeine and CGA were obtained with $30: 1$ (ml/g) liquid-solid ratio and 60 min of extraction time and the lowest caffeine and CGA yields were obtained for the liquid-solid ratio of 10:1 (ml/g) with $60 \mathrm{~min}$ of extraction time. Then, it can be concluded that the highest yield of caffeine and CGA were obtained using a 4:1 ratio mole of ChCl-sorbitol, a $30: 1(\mathrm{ml} / \mathrm{g})$ liquid-solid ratio and $60 \mathrm{~min}$ of extraction time. These conditions correspond to the sample number 2 (Table 1). On the basis of these results, the RSM-Box-Behnken design was used to obtain the optimal conditions. One of the 26 possible optimal conditions corresponded to a mole ratio of ChCl-sorbitol of 4.17:1, an extraction time of $59.94 \mathrm{~min}$, and a liquidsolid ratio of $29.96: 1(\mathrm{ml} / \mathrm{g})$. Table 2 summarizes the yields of caffeine and CGA obtained using the RSMBox-Behnken design and those obtained experimentally. Moreover, the yields of caffeine and CGA obtained using maceration and those using the NADES ChClsorbitol extraction of GCB are compared in Table 3, showing that, although the caffeine levels extracted with both methods were very similar, the yield of CGA was $297 \%$ higher by the NADES extraction than by the maceration. Fig. 3 shows the chromatograms
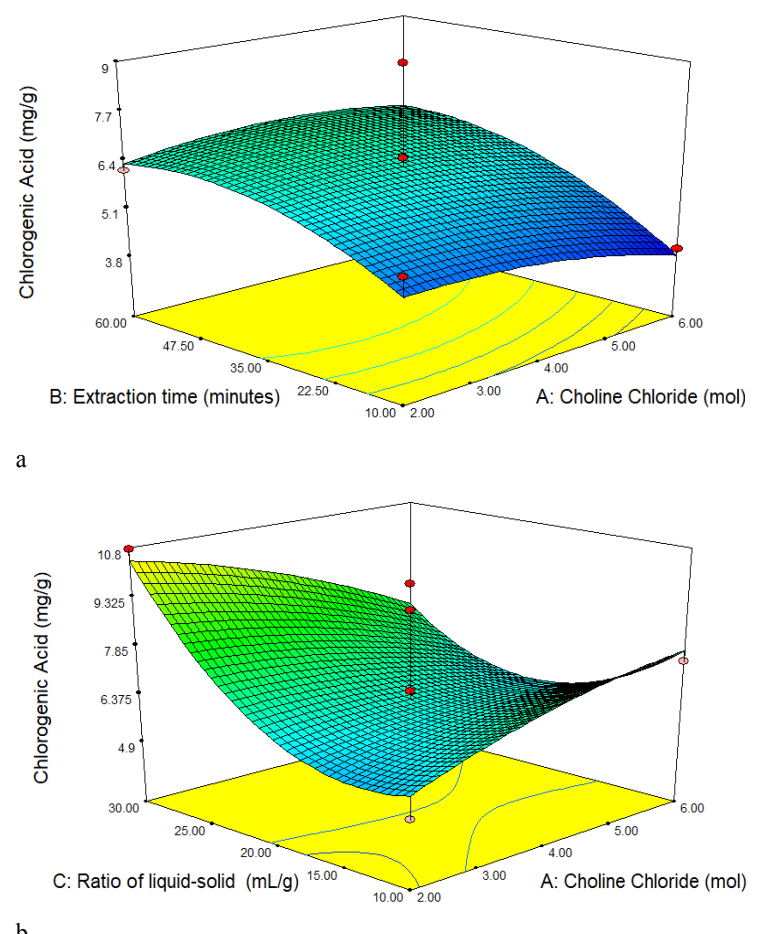

b

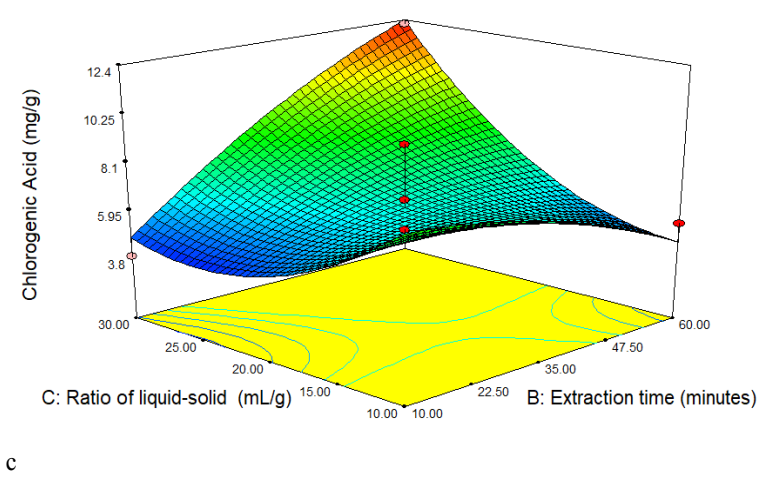

Fig. 2: Three-dimensional surface response of the relationships for CGA

(a) Extraction time and choline chloride, (b) liquid-solid ratio and choline chloride, and (c) liquid-solid ratio and extraction time vs. chlorogenic acid (CGA) 
corresponding to the conditions summarized in Table 3, in which the retention times for caffeine and CGA were observed at 9 and $12 \mathrm{~min}$, respectively.

The analysis of variance by RSM with quadratic regression models for caffeine showed that the correlation coefficient $(r)$ was 0.8987 , indicating that the independent variable affects the dependent variable (response), the standard deviation was determined to be 0.40 and $\mathrm{CV}$ was $10.81 \%$. The $\mathrm{F}$ value obtained from the lack-of-fit test was 0.33 ( $>>0.05)$, meaning that noise was not significant to pure errors, thus, suggesting the suitability of this RSM model. The F value of the model (6.09) shows that the model was significant, and only $0.93 \%$ of the probability of the model $\mathrm{F}$ value was due to interference. Overall, the significance value of the model, the value of $p$ Prop $>F$ (0.0093) smaller

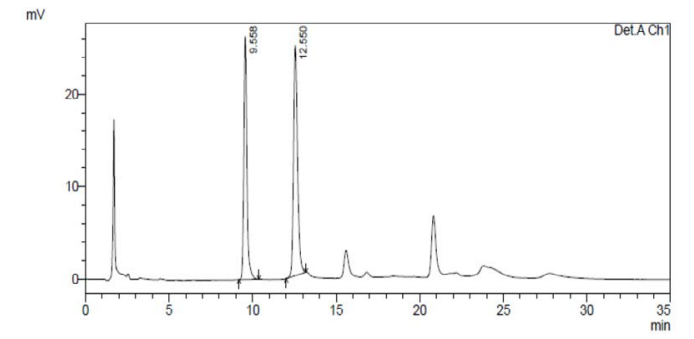

a

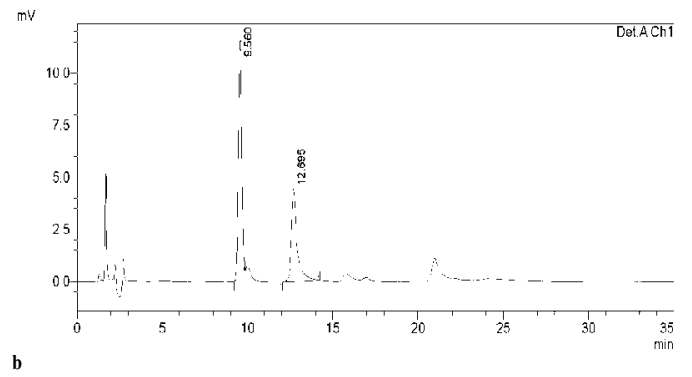

Fig. 3: Chromatographic profile of caffeine and CGA (a) Highest yield of choline chloride, sorbitol (4:1, NADES) extract of green coffee bean (GCB) powder, peak 1- chlorogenic acid (CGA) with $t_{R}$ of 9.5 min and peak 2-caffeine with $t_{R}$ of 12.5 min (b) $70 \%$ ethanol extract of GCB, peak 1- CGA with $t_{R}$ of $9.5 \mathrm{~min}$ and peak 2- caffeine with $t_{R}$ of $12.6 \mathrm{~min}$ than 0.05 , indicates that the model was significant and suitable for our work.

The analysis of variance by RSM with quadratic regression models for CGA in a similar manner. Again, the value obtained for the correlation coefficient $(\mathrm{r}=0.8510)$ indicated that the independent variable affected the dependent variable (response). The standard deviation was calculated to be 1.34 , and CV was $20.01 \%$. The F value from lack-of-fit test was $0.46(\mathrm{p}>0.05)$, suggesting the suitability of the model because noise was not significant to pure errors. The $\mathrm{F}$ value of the model (4.44) indicated that the model was significant and only $3.10 \%$ of the probability of the model $F$ value was due to interference. From the significance value of the model, the value of $p$ Prop $>$ F (0.0031) smaller than 0.05 , the model was significant and could be accepted.

Inhibition of PPL was investigated by measuring the absorbance of p-nitrophenol, which is the final product of the hydrolysis of the substrate p-NPB by PPL. Table 4 displays the results of the inhibitory activity and $\mathrm{IC}_{50}$ values of the sample, orlistat, caffeine and CGA standard, and NADES ChCl-sorbitol. It was found that the NADES ChCl-sorbitol had no inhibitory activity against the PPL enzyme. $\mathrm{IC}_{50}$ values of orlistat, caffeine and CGA standards and the samples were 8.86, 15.59, 11.90 , and $32.46 \mu \mathrm{g} / \mathrm{ml}$, respectively.

Differences in the results obtained with maceration in this study and those reported in Navarra et al. might be due to differences in the original raw materials, the process of maceration, and the tools used for the analysis ${ }^{[12]}$. As caffeine and CGA are secondary metabolites, their contents found in herbal products are influenced by environmental factors such as growing or geographical conditions that include land, altitude, season, and rainfall and other factors such as harvest time or planting density ${ }^{[15]}$. The process of maceration of GCB with $70 \%$ ethanol described in Navarra et al.

TABLE 2: COMPARISON OF THE YIELDS OF CAFFEINE AND CGA OBTAINED BY RSM-BOX-BEHNKEN DESIGN AND EXPERIMENTAL RESULTS

\begin{tabular}{lccccc}
\hline Comparison & $\begin{array}{c}\text { Ratio of } \mathrm{ChCl}: \\
\text { sorbitol }(\mathrm{mol})\end{array}$ & $\begin{array}{c}\text { Extraction } \\
\text { time }(\mathrm{min})\end{array}$ & $\begin{array}{c}\text { Ratio of liquid to } \\
\text { solid }(\mathrm{g} / \mathrm{ml})\end{array}$ & $\begin{array}{c}\text { Caffeine level } \\
\text { actual } \pm \text { SD }(\mathrm{mg} / \mathrm{g})\end{array}$ & $\begin{array}{c}\text { CGA level } \\
\text { actual } \pm \text { SD }(\mathrm{mg} / \mathrm{g})\end{array}$ \\
\hline RSM-Box-Behnken design & $4.17: 1$ & 59.94 & $29.96: 1$ & 5.90 & 12.26 \\
Experimental results & $4: 1$ & 60 & $30: 1$ & $4.35 \pm 0.47$ & $11.21 \pm 0.088$ \\
\hline
\end{tabular}

RSM is response surface methodology, CGA is chlorogenic acid, $\mathrm{ChCl}$ is choline chloride, SD is standard deviation for $\mathrm{n}=3$ observations

TABLE 3: COMPARISON OF EXTRACTION BY MACERATION OF GCB POWDER AND UAE WITH CHCL AND SORBITOL NADES MIXTURE

\begin{tabular}{lcccc}
\hline Extraction method & Caffeine $(\mathrm{mg} / \mathrm{g})$ & CGA $(\mathrm{mg} / \mathrm{g})$ & \% increase in caffeine & \% increase in CGA \\
\hline Maceration & 3.03 & 3.08 & \multirow{2}{*}{$93.72 \%$} & $297 \%$ \\
NADES ChCl sorbitol $(4: 1)$ & 5.87 & 12.24 & & \\
\hline
\end{tabular}


involved stirring with a magnetic stirrer for $24 \mathrm{~h}$. In the present study, maceration was carried out with normal stirring after soaking for $6 \mathrm{~h}$ in accordance with procedures from Indonesian Herbal Pharmacopoeia. This difference in stirring could have affected the final yields. Thus, quick stirring using a magnetic stirrer would increase the speed of dissolution of secondary metabolites in ethanol. Moreover, magnetic stirring for $24 \mathrm{~h}$ would cause vibration with the concomitant increase in the kinetic energy. This increase in energy would be accompanied by an increase in the frequency of interactions between solvents and molecules of caffeine or CGA, which would dissolve quickly. Furthermore, a quick stirring can also reduce obstacle layers that might interfere with the dissolution of active substances ${ }^{[16]}$. The different methods and tools used for the analyses could also affect the results ${ }^{[17]}$. However, the amount of caffeine and CGA extracted by $70 \%$ ethanol from GCB in this study is lower than the highest yield obtained from the GCB extracted using the NADES ChCl-sorbitol, demonstrating that the extraction method using the NADES ChCl-sorbitol with UAE was more effective than conventional methods. Additionally, it confirmed the good extraction capabilities of NADES ${ }^{[18]}$. In the preparation of the NADES ChCl-sorbitol, water was added $(50 \% \mathrm{v} / \mathrm{v})$ to reduce viscosity ${ }^{[19]}$. The addition of water increased the transfer of compounds from the plant matrix to the solvent, thereby increasing the efficiency of the extraction ${ }^{[20]}$. It is worth noting that the NADES comprised of a large molecule with hydrogen bonds, and when the water content is higher than $50 \% \mathrm{v} / \mathrm{v}$, these interactions may become unstable. UAE is used to assist the extraction of GCB powder using $\mathrm{ChCl}$ sorbitol. In this study, the extraction with the NADES ChCl-sorbitol was combined with UAE to enhance the efficiency of the extraction and reduce excessive energy use, with the idea of developing an improved environmentally friendly extraction method ${ }^{[21]}$. Since the NADES ChCl-sorbitol is a biodegradable, natural, and nontoxic solvent ${ }^{[6]}$, the NADES-UAE combination constituted a cheap, fast, environmentally friendly, and easy-to-use method that could be used on a laboratory scale $^{[21,22]}$.

NADES are mixtures of HBA and HBD compound with a certain ratio and the mixtures will make the eutectic system, because the mixtures have a melting point lower than the melting point of each compound ${ }^{[4,23]}$. Usually, that system form a liquid below $100^{\circ[24]}$. The eutectic mixture system could be used as a solvent. The presence of hydrogen bonds and the interaction of Van der Waals are the main drivers of this phenomenon ${ }^{[25]}$. In this study, the optimum mole ratio of ChCl-sorbitol was found to be $4: 1$. The smaller yield obtained with the mole ratio of 2:1 might be due to the decrease in the number of moles of $\mathrm{ChCl}$ resulting in the weakening of the hydrogen bonds in the NADES system, which could affect the mechanism of dissolution of active compounds in the extraction process ${ }^{[20]}$. On the other hand, in the case of the mole ratio of $6: 1$, the higher amount of $\mathrm{ChCl}$ affords a thicker NADES with reduced efficiency in the extraction of secondary metabolites from $\mathrm{GCB}^{[24]}$. In the present study, the NADES $\mathrm{ChCl}$-sorbitol was stable for more than $7 \mathrm{~d}$ and no sedimentation was observed. The stability of NADES correlated with the presence of strong hydrogen bonds between solutes and solvent molecules, resulting in a higher extraction ability of the NADES ${ }^{[18]}$. It was found that the 60-min extraction time was the best condition for extracting the highest amount of caffeine and CGA, compared to the extraction times of 10 and $35 \mathrm{~min}$. For CGA, it was necessary to consider the length of extraction time, since CGA is a polyphenolic compound that can be easily degraded by ultrasonic exposure ${ }^{[25]}$. Regarding the liquid-solid ratio, it was found that $30: 1$ $(\mathrm{ml} / \mathrm{g})$ was the best condition for extracting caffeine and CGA in comparison with the ratios of 10:1 (ml/g) and 20:1 (ml/g). The liquid-solid ratio provides a comparison of the amount of solvent added $(\mathrm{ml})$ to the GCB powder $(\mathrm{g})$ that will be extracted. Higher amounts

TABLE 4: INHIBITORY ACTIVITY OF THE SAMPLE, ORLISTAT, CAFFEINE, CGA AND NADES SOLVENT

\begin{tabular}{|c|c|c|c|c|c|}
\hline \multirow{2}{*}{$\begin{array}{l}\text { Concentration } \\
\text { of sample }(\mu \mathrm{g} / \mathrm{ml})\end{array}$} & \multicolumn{5}{|c|}{ \% Inhibition } \\
\hline & Sample & Orlistat & Caffeine Standard & CGA Standard & $\begin{array}{c}\text { NADES Choline Chloride- } \\
\text { Sorbitol }(4: 1)\end{array}$ \\
\hline 200 & 82.02 & 93.29 & 83.88 & 200 & \\
\hline 100 & 78.58 & 89.41 & 81.44 & 100 & \\
\hline 50 & 77.94 & 77.31 & 76.19 & 50 & -27.01 \\
\hline 25 & 68.01 & 55.57 & 64.60 & 25 & -31.09 \\
\hline 12.5 & 48.93 & 52.38 & 38.64 & 12.5 & \\
\hline 6.25 & 44.71 & 50.60 & 34.04 & 6.25 & \\
\hline $\mathrm{IC}_{50}(\mu \mathrm{g} / \mathrm{ml})$ & 32.46 & 8.86 & 15.59 & 11.90 & \\
\hline
\end{tabular}

$\mathrm{IC}_{50}$ is the half maximal inhibitory concentration, CGA is chlorogenic acid, NADES is natural deep eutectic solvent 
of solvent accelerates the phenomenon of mass transfer due to the difference in concentration between matrix sample and solvent ${ }^{[26]}$. When considering the liquidsolid ratio, the purity of the extract and the efficiency in extraction must also be taken into account. Thus, the process becomes costly if the amount of solvent used is excessive, whereas an insufficient amount of solvent may cause the extraction of secondary metabolites from the plant to be ineffective. The average liquid-solid ratio often used in research ranges from 4.6:1 to $60: 1 \mathrm{ml} / \mathrm{g}^{[26]}$.

The PPL enzyme activity was evaluated by measuring the absorbance of p-nitrophenol, the final product of the hydrolysis of the p-NPB substrate by PPL. The $\mathrm{IC}_{50}$ of the GCB extracted using the NADES ChCl-sorbitol with the highest amount of caffeine and CGA was $32.46 \mu \mathrm{g} / \mathrm{ml}$. Since the approximate content of caffeine and CGA in the sample was 0.0027 and $0.0577 \mu \mathrm{g} / \mathrm{ml}$, respectively, it can be concluded that the $\mathrm{IC}_{50}$ level for caffeine and CGA in the sample is lower than those in the caffeine and CGA standards. This demonstrated the potentiation effect in PPL enzyme inhibition by caffeine and CGA in the GCB extracted using the NADES ChCl-sorbitol. This study also proved that on the Robusta GCB extract obtained using NADES ChCl-sorbitol (4:1) with UAE exhibited PPL inhibitory activity. The compounds responsible for the inhibitory effect are most likely caffeine and CGA, since both the standards caffeine and CGA inhibited PPL enzyme. The mechanism of lipase inhibition by CGA has been reported to proceed through binding noncovalently and interacting with the catalytic triad in PPL (serine, histidine, and aspartic acid) ${ }^{[27]}$. Meanwhile, caffeine acts as a lipase inhibitor by binding free enzymes and enzyme-substrate complexes (short-chain fatty acid substrate $)^{[28]}$. Thus, when binding free enzymes, caffeine hampers the reaction between the enzyme and the substrate, thereby preventing the formation of the product. Similarly, caffeine hinders the conversion of the substrate into products through the binding to the enzyme-substrate complex ${ }^{[29]}$.

Based on the current data, an optimal green extraction method that involved the use of $\mathrm{ChCl}$-sorbitol as NADES for the extraction of caffeine and CGA from Robusta GCB was developed. The combination of a biodegradable, natural, and nontoxic solvent with UAE provided access to a cheap, fast, environmentally friendly, and easy-to-use method for the extraction of active components from plants. A thorough screening of conditions based on RSM analysis revealed that the optimum conditions that led to the maximum yields of caffeine and CGA were a ChCl-sorbitol ratio of 4.17:1, $59.94 \mathrm{~min}$ of extraction time, and a liquid-solid ratio of 29.96:1 (ml/g). Noteworthily, the yield of CGA obtained using the NADES was $297 \%$ higher than that obtained with the maceration (conventional) method. The GCB extract obtained using the present method inhibited the PPL enzyme, with an $\mathrm{IC}_{50}$ value of $32.46 \mu \mathrm{g} / \mathrm{ml}$.

\section{Acknowledgements:}

The authors thank the National Quality Control Laboratory of Drugs and Food-National Agency of Drug and Food Control for providing the HPLC instrument. Indonesian Coffee and Cocoa Research Institute, Jember, East Java and Riset Perkebunan Nusantara (RPN), Bogor, West Java which facilitates altering the GCB into powder.

\section{Financial interest and scholarship:}

This work was funding by Ministry of Research, Technology and Higher Education, Republic of Indonesia via Hibah Penilitian Thesis Magister 2019.

\section{REFERENCES}

1. Higdon JV, Frei B. Coffee and health: A review of recent human research. Crit Rev Food Sci Nutr 2006;46(2):101-23.

2. Mohamed GA, Ibrahim SRM, Elkhayat ES, Eldine RS. Natural antiobesity agents. Bull Fac Pharm Cairo Univ 2014;52(2):269-84.

3. Kerton FM. Alternative solvents for green chemistry. Cambridge: The Royal Society of Chemistry (RSC) Publishing; 2009.

4. Smith EL, Abbott AP, Ryder KS. Deep eutectic solvents (DESs) and their Applications. Chem Rev 2014;114(21):11060-82.

5. Li X, Row KH. Development of deep eutectic solvents applied in extraction and separation. J Sep Sci 2016;39(18):1-46.

6. Espino M, De los Ángeles Fernández M, Gomez FJV, Silva MF. Natural designer solvents for greening analytical chemistry. TrAC Trends Anal Chem 2016;76:126-36.

7. Duan L, Dou LL, Guo L, Li P, Liu EH. Comprehensive evaluation of deep eutectic solvents in extraction of bioactive natural products. ACS Sustainable Chem Eng 2016;4(4):240511.

8. Dai Y, Verpoorte R, Choi YH. Natural deep eutectic solvents providing enhanced stability of natural colorants from safflower (Carthamus tinctorius). Food Chem 2014;159:116-21.

9. Zhao BY, Xu P, Yang FX, Wu H, Zong MH, Lou WY. Biocompatible deep eutectic solvents based on choline chloride: characterization and application to the extraction of rutin from Sophora japonica. ACS Sustainable Chem Eng 2015;3(11):2746-55.

10. Huang Y, Feng F, Jiang J, Qiao Y, Wu T, Voglmeir J, et al. Green and efficient extraction of rutin from Tartary buckwheat hull by using natural deep eutectic solvents. Food Chem 2017;221:1400-5.

11. Yuniarti E, Saputri FC, Mun'im A. Application of the natural deep eutectic solvent choline chloride- sorbitol to extract 
chlorogenic acid and caffeine from green coffee beans (Coffea canephora). J Appl Pharm Sci 2019;8:1-9.

12. Navarra G, Moschetti M, Guarrasi V, Mangione MR, Militello V, Leone M. Simultaneous Determination of Caffeine and Chlorogenic Acids in Green Coffee by UV/Vis Spectroscopy. J Chem 2017;2017:6435086.

13. Wei Z, Qi X, Li T, Luo M, Wang W, Zu Y, et al. Application of natural deep eutectic solvents for extraction and determination of phenolics in Cajanus cajan leaves by ultra performance liquid chromatography. Sep Purif Technol 2015;149:237-44.

14. Dechakhamphu A, Wongchum N. Screening for anti-pancreatic lipase properties of 28 traditional Thai medicinal herbs. Asian Pac J Trop Biomed 2015;5(12):1042-5.

15. Zhang J, Wider B, Shang H, Li X, Ernst E. Quality of herbal medicines: Challenges and solutions. Complement Ther Med 2012;20(1-2):100-6.

16. Chen Y, Wang J, Flanagan DR. Fundamental of diffusion and dissolution. developing solid oral dosage forms. Pharmaceutical Theory and Practice. Cambridge, Massachusetts, United States: Academic Press; 2017.

17. Melboe L. Role of the "differently-abled" researcher: Challenges and solutions in inclusive research Le rôle de la chercheuse (sans déficience intellectuelle): défis et solutions liés à la recherche inclusive. Alter - Eur J Disability Res 2018;12(4):225-37.

18. Dai Y, Spronsen J Van, Witkamp G. Natural deep eutectic solvents as new potential media for green technology. Anal Chim Acta 2013;766:61-68.

19. Dai Y, Witkamp GJ, Verpoorte R, Choi YH. Tailoring properties of natural deep eutectic solvents with water to facilitate their applications. Food Chem 2015;187:14-19.

20. Joki S, Marina CB, Senka V. New perspective in extraction of plant biologically active compounds by green solvents. Food Bioproducts Process 2018;9:52-73.
21. Abdul R, Yahya A, Attana N. Processing an overview of cosmeceutically relevant plant extracts and strategies for extraction of plant-based bioactive compounds. Food Bioproducts Process 2018;112:69-85.

22. Ahmad I, Pertiwi AS, Kembaren YH, Rahman A, Mun'im, A. Application of natural deep eutectic solvent-based ultrasonic assisted extraction of total polyphenolic and caffeine content from coffee beans (Coffea beans $\mathrm{L}$ ) for instant food products. J Appl Pharm Sci 2018;8(08):138-43.

23. Vian M, Breil C, Vernes L, Chaabani E, Chemat F. Green solvents for sample preparation in analytical chemistry. Curr Opin Green Sustain Chem 2017;5:44-48.

24. Zhang Q, De Oliveira Vigier K, Royer S, Jerome F. Deep eutectic solvents: syntheses, properties and applications. Chem Soc Rev 2012;41:7108-46.

25. Lianfu Z, Zelong L. Optimization and comparison of ultrasound/microwave assisted extraction (UMAE) and ultrasonic assisted extraction (UAE) of lycopene from tomatoes. Ultrason Sonochem 2008;15:731-7.

26. Oreopoulou A, Tsimogiannis D, Oreopoulou V. Extraction of polyphenols from aromatic and medicinal plants: an overview of the methods and the effect of extraction parameters. Polyphenols in Plants. 2nd ed. Cambridge, Massachusetts, United States: Academic Press; 2018.

27. Hu B, Cui F, Yin F, Zeng X, Sun Y, Li Y. Caffeoylquinic acids competitively inhibit pancreatic lipase through binding to the catalytic triad. Int J Biol Macromol 2015;80:529-35.

28. Wikiera A, Mika M, Żyła K. Methylxanthine Drugs Are Human Pancreatic Lipase Inhibitors. Pol J Food Nutr Sci 2012;62(2):109-13.

29. Dougall IG, Unitt J. Evaluation of the Biological Activity of Compounds: Techniques and Mechanism of Action Studies. The Practice of Medicinal Chemistry. Cambridge, Massachusetts, United States: Academic Press; 2015. 